\title{
PEMBERIAN SUPLEMEN KOMBINASI KALSIUM, VITAMIN B6, VITAMIN C DAN VITAMIN D TERHADAP PENURUNAN TINGKAT NYERI DISMENOREA
}

\author{
THE EFFECT OF CALCIUM, VITAMIN B6, VITAMIN C AND VITAMIN D \\ COMBINATIONS TO DECREASE LEVELS OF DISMENOREA PAIN
}

\author{
Indriastuti Cahyaningsih*, Pinasti Utami, Sri Utami \\ Program Studi Farmasi, Fakultas Kedokteran dan Ilmu Kesehatan, \\ Universitas Muhammadiyah Yogyakarta \\ J1. Lingkar Selatan Taman Tirto, Kasihan, Bantul, Yogyakarta 55183 \\ *Penulis Korespodensi, email: ndree_chy@yahoo.com
}

\begin{abstract}
ABSTRAK
Dismenorea biasanya menyebabkan nyeri atau kram pada bagian perut yang dapat mengganggu aktivitas dan mengurangi kualitas hidup. Nyeri dan kram tersebut karena peningkatan prostaglandin. Kalsium berfungsi untuk mengurangi nyeri dan kram saat menstruasi. Vitamin B6 dan vitamin D dapat membantu menurunkan tingkat kecemasan pada sindrom premenstruasi. Tujuan dari penelitian ini adalah untuk mengetahui pengaruh pemberian suplemen kombinasi kalsium terhadap nyeri dismenorea. Jenis penelitian ini adalah quasi experimental. Sebanyak 70 orang mahasiswi Fakultas Kedokteran dan Ilmu Kesehatan Universitas Muhammadiyah Yogyakarta yang mengalami nyeri dismenorea dibagi menjadi 2 kelompok yaitu kelompok kontrol yang tidak mendapatkan perlakuan dan kelompok uji yang mendapatkan perlakuan berupa konsumsi suplemen kombinasi kalsium $250 \mathrm{mg}$, vitamin B6 $15 \mathrm{mg}$, vitamin C $1000 \mathrm{mg}$, dan vitamin D $300 \mathrm{mg}$, dalam bentuk tablet effervescent yang diberikan pada hari ke 15 siklus menstruasi hingga hari pertama menstruasi. Pengukuran skala nyeri Visual Analogue Scale (VAS) dilakukan pada hari ke 15 siklus menstruasi dan hari pertama menstruasi. Data dianalisis menggunakan metode paired sample t test dan independent sample t test. Hasil analisis dengan uji independent sample T test menunjukkan terdapat penurunan skala nyeri VAS kelompol kontrol dan kelompok perlakuan dengan nilai penurunan berturut-turut $0,80 \pm 1,64$ dan 1,74 $\pm 1,52$ ( $p$-value $0,015<0,05$ ). Dapat disimpulkan pemberian suplemen kombinasi kalsium, vitamin B6, vitamin D, dan vitamin $\mathrm{C}$ dalam bentuk tablet effervescent dapat menurunkan skala nyeri pada mahasiswi yang mengalami dismenorea.
\end{abstract}

Kata kunci: Dismenorea, Visual Analoge Scale (VAS), Calcium, Vitamin B6, Vitamin D, Vitamin C

\section{ABSTRACT}

Dysmenorrhea is a condition that can interfere daily activity and reduce quality of life. These pain and cramps due to increased prostaglandins. Calcium serves to reduce pain and cramps during menstruation. Vitamin B6 and vitamin D can help to reduce anxiety levels in premenstrual syndrome. The purpose of this study was to determine the effect 
of calcium combination supplement on dysmenorrhea pain of the respondents. This research use quasi-experimental method. A total of 70 students of Faculty of Medicine and Health Sciences of Muhammadiyah University of Yogyakarta who suffered from Dysmenorrhea pain were divided into 2 groups: the control group that did not get treatment and the test group that received treatment which was to consume supplement combination of calcium $250 \mathrm{mg}$, vitamin B6 $15 \mathrm{mg}$, vitamin C $1000 \mathrm{mg}$, and vitamin D $300 \mathrm{mg}$ in the form of effervescent tablets administered on the $15^{\text {th }}$ day of the menstrual cycle until the first day of menstruation. The measurement with the VAS pain scale was performed on the $15^{\text {th }}$ day of the menstrual cycle and the first day of menstruation. Data were analyzed using paired sample $t$ test and independent sample $t$ test. The result of the analysis with independent sample t test showed that there was a decrease of VAS pain scale in control group and treatment group with decreasing for $0.80 \pm 1.64$ and $1.74 \pm 1.52$ consecutively ( $p$-value $0.015<0.05$ ). In conclusion supplement combination of calcium, vitamin B6, vitamin $D$, and vitamin $C$ administration in the form of effervescent tablets can reduce the scale of pain in women with dysmenorrhea.

Keywords: Dysmenorrhea, Visual Analogue Scale (VAS), Calcium, Vitamin B6, Vitamin $D$, Vitamin C

\section{PENDAHULUAN}

Menstruasi merupakan suatu keadaan dimana terjadinya pengeluaran darah dan lendir yang dikeluarkan melalui vagina secara periodik dan siklik dimulai pada 14 hari setelah ovulasi (Proverawati \& Misaroh, 2009). Nyeri saat menstruasi atau dismenorea merupakan nyeri atau kram perut yang sering dirasakan saat wanita mengalami menstruasi. Mahmudiono (2011), menerangkan bahwa angka kejadian dismenorea primer pada remaja wanita yang berusia 14-19 tahun di Indonesia sekitar 54,89\%. Lestari (2013) juga menyebutkan bahwa angka kejadian cukup banyak terjadi di Indonesia yaitu sebesar $64,25 \%$ yang terdiri dari $54,89 \%$ dismenorea primer dan $9,36 \%$ dismenorea sekunder.

Banyak wanita yang mengalami nyeri menstruasi mengeluhkan berkurangnya kualitas hidup mereka. Oleh karena itu, dibutuhkan tindakan khusus terhadap keluhankeluhan tersebut agar dapat meningkatkan kualitas hidup dari wanita remaja hingga wanita dewasa khususnya yang sering mengalami nyeri saat menstruasi.

Penelitian yang dilakukan oleh Fen Tih et al. (2017) membuktikan bahwa pemberian suplemen kalsium pada wanita yang berusia 19-23 tahun yang mengalami dismenorea dapat mengurangi skala nyeri pada siklus menstruasi berikutnya. Penelitian ini juga menjelaskan bahwa magnesium pada wanita yang mengalami nyeri dismenorea dapat mengurangi gejala sindrom premenstruasi dikarenakan magnesium memiliki efek relaksasi terhadap stimulasi di neuromuscular. Vitamin B6 dan vitamin D juga memlliki efek terhadap sindrom premenstruasi.

Penelitian lain yang dilakukan oleh Soviana dan Putri (2017) menunjukkan hasil bahwa konsumsi vitamin B6 yang cukup dan sesuai dengan kebutuhan dapat membantu mengurangi sindrom premenstruasi. Moini et al. (2016) juga menyebutkan bahwa konsumsi vitamin D selama 8 minggu pada wanita yang kurang asupan vitamin D dapat membantu menurunkan intensitas nyeri pada wanita yang mengalami nyeri dismenorea primer. Penelitian ini bertujuan untuk mengetahui pengaruh pemberian suplemen 
kombinasi kalsium terhadap penurunan tingkat nyeri dismenorea pada wanita yang mengalami dismenorea.

\section{METODE PENELITIAN}

\section{Bahan dan Alat}

Populasi adalah mahasiswa Fakultas Kedokteran dan Ilmu Kesehatan (FKIK) UMY yang mengalami nyeri dismenore. Skala nyeri dismenorea diukur dengan Visual Analoge Scale (VAS).

\section{Jalannya Penelitian}

Jenis penelitian ini adalah quasi experimental dengan rancangan menggunakan 2 grup pretest dan posttest design. Penelitian ini dilakukan di Universitas Muhammadiyah Yogyakarta (UMY) pada bulan Oktober 2017 hingga Mei 2018. Populasi adalah mahasiswi Fakultas Kedokteran dan Ilmu Kesehatan (FKIK) yang mengalami nyeri dismenorea. Subjek penelitian adalah 70 orang mahasiswa perempuan di FKIK. Kriteria inklusi adalah mahasiswi yang berusia 17-25 tahun dan memiliki siklus menstruasi yang teratur. Kriteria ekslusi adalah sudah menikah, minum obat penghilang nyeri pasa saat penelitian, dan tidak patuh terhadap regimen yang disarankan.

Subjek penelitian dibagi menjadi 2 kelompok yaitu kelompok kontrol dan kelompok uji. Kelompok kontrol tidak akan mendapatkan perlakuan dan kelompok uji akan mendapatkan perlakuan berupa konsumsi suplemen kombinasi kalsium, vitamin $\mathrm{B} 6$, vitamin $\mathrm{D}$, dan vitamin $\mathrm{C}$ dalam bentuk tablet effervescent yang diberikan sebanyak 1 kali sehari 1 tablet pada hari ke 15 siklus menstruasi hingga hari pertama menstruasi. Jumlah subjek pada masing-masing kelompok adalah 35 orang.

Skala nyeri dismenorea diukur dengan Visual Analoge Scale (VAS) yang sebelumnya sudah dibakukan oleh Jensen (2013). VAS merupakan skala yang dapat menggambarkan tingkat nyeri yang dialami oleh seseorang. Rentang nyeri pada skala ini diibaratkan dengan garis lurus sepanjang $10 \mathrm{~cm}$ dengan atau tanpa tanda tiap sentimeter. Pada kedua ujung garis tersebut terdapat tanda yang berupa angka atau pernyataan deskriptif. Ujung yang satu mewakili tidak ada nyeri dan ujung yang satunya mewakili nyeri yang paling parah. Skala nyeri VAS diukur sebanyak 2 kali yaitu pada hari ke 15 siklus menstruasi dan hari pertama menstruasi. Data yang didapat akan dianalisis menggunakan metode paired sample t test dan independent sample t test.

\section{HASIL DAN PEMBAHASAN}

Penelitian ini bertujuan untuk mengetahui pengaruh pemberian suplemen kombinasi kalsium terhadap nyeri dismenorea. Subjek penelitian adalah 70 mahasiswi yang mengalami dismenorea saat menstruasi. Karakteristik subjek dibagi berdasarkan program studi, usia, semester, dan pekerjaan. Berdasarkan Tabel I, dapat dilihat bahwa pada kelompok kontrol dan perlakuan responden paling banyak terdapat pada program studi Ilmu Keperawatan yaitu sebanyak 11 orang (31,4\%). Berdasarkan usia kelompok kontrol terbanyak adalah usia 19 tahun yaitu sebanyak 10 orang $(28,6 \%)$ dan usia kelompok perlakuan paling banyak adalah usia 19 dan 21 tahun sebanyak 10 orang $(28,6 \%)$. Berdasarkan semester pada kelompok kontrol dan kelompok perlakuan 
terbanyak adalah semester 2, 4 dan 6 yaitu sebanyak 9 orang $(25,7 \%)$. Berdasarkan pekerjaan baik pada kelompok kontrol maupun kelompok perlakuan semua responden adalah mahasiswa yaitu sebanyak 70 orang $(100,0 \%)$.

Tabel I. Gambaran Karakteristik Responden Berdasarkan Program Studi, Usia, Jenis Kelamin, Semester, dan Pekerjaan

\begin{tabular}{|c|c|c|c|c|}
\hline \multirow[t]{2}{*}{ Karakteristik Responden } & \multicolumn{2}{|c|}{ Kontrol } & \multicolumn{2}{|c|}{ Perlakuan } \\
\hline & $\mathbf{F}$ & $\%$ & $\mathbf{F}$ & $\%$ \\
\hline \multicolumn{5}{|l|}{ Prodi } \\
\hline Program Studi Farmasi & 8 & 22,9 & 8 & 22,9 \\
\hline $\begin{array}{l}\text { Program Studi Pendidikan } \\
\text { Dokter }\end{array}$ & 8 & 22,9 & 8 & 22,9 \\
\hline $\begin{array}{l}\text { Program Studi Kedokteran } \\
\text { Gigi }\end{array}$ & 8 & 22,9 & 8 & 22,9 \\
\hline \multirow[t]{2}{*}{$\begin{array}{l}\text { Program Studi Ilmu } \\
\text { Keperawatan }\end{array}$} & 11 & 31,4 & 11 & 31,4 \\
\hline & 35 & 100,0 & 35 & 100,0 \\
\hline \multicolumn{5}{|l|}{ Usia } \\
\hline 17 Tahun & 2 & 5,7 & 0 & 0,0 \\
\hline 18 Tahun & 6 & 17,1 & 5 & 14,3 \\
\hline 19 Tahun & 10 & 28,6 & 10 & 28,6 \\
\hline 20 Tahun & 6 & 17,1 & 5 & 14,3 \\
\hline 21 Tahun & 8 & 22,9 & 10 & 28,6 \\
\hline 22 Tahun & 3 & 8,6 & 5 & 14,3 \\
\hline \multicolumn{5}{|l|}{ Semester } \\
\hline 2 & 9 & 25,7 & 9 & 25,7 \\
\hline 4 & 9 & 25,7 & 9 & 25,7 \\
\hline 6 & 9 & 25,7 & 9 & 25,7 \\
\hline 8 & 8 & 22,9 & 8 & 22,9 \\
\hline \multicolumn{5}{|l|}{ Pekerjaan } \\
\hline Mahasiswa & 35 & 100,0 & 35 & 100,0 \\
\hline
\end{tabular}

Tabel II. Perbedaan Skala Nyeri Sebelum (Pre) dan Sesudah (Post) Pemberian Suplemen Kombinasi Kalsium Pada Kelompok Kontrol dan Perlakuan Dengan Uji Paired Sample T Test

\begin{tabular}{ccccc}
\hline \multicolumn{2}{c}{ Kelompok } & Mean \pm SD & N & p-value \\
\hline \multirow{2}{*}{ Kontrol } & Sebelum & $6,00 \pm 1,57$ & \multirow{2}{*}{35} & 0,007 \\
& Sesudah & $5,20 \pm 2,01$ & & \\
\hline \multirow{2}{*}{ Perlakuan } & Sebelum & $5,74 \pm 1,75$ & \multirow{2}{*}{35} & 0,000 \\
& Sesudah & $4,00 \pm 2,01$ & & \\
\hline
\end{tabular}


Berdasarkan Tabel II, diketahui bahwa skala nyeri pada kelompok kontrol mendapatkan nilai mean atau rata-rata nilai skala VAS pre test yaitu 6,00 dan post test yaitu 5,20 dengan $p$-value 0,007 . Karena nilai $p$-value $0,007<0,05$ maka terdapat pengaruh yang signifikan dari pre test terhadap pos test, sehingga dapat disimpulkan ada perbedaan yang signifikan antara skala nyeri dismenorea sebelum dan sesudah dilakukannya penelitian pada kelompok kontrol. Pada Tabel II juga dapat dilihat kelompok perlakuan yang diberikan suplemen kombinasi kalsium mendapatkan nilai mean atau rata-rata nilai skala VAS pre test yaitu 5,74 dan post-test yaitu 4,00 dengan nilai $p$-value 0,000 . Karena nilai $p$-value $0,000<0,05$ maka terdapat pengaruh yang signifikan dari pre test terhadap post test, sehingga dapat disimpulkan bahwa ada perbedaan yang signifikan antara skala nyeri dismenorea sebelum dan sesudah pemberian suplemen kombinasi kalsium.

Tabel III. Perbedaan selisih nyeri pada kelompok kontrol dan perlakuan dengan uji independent sample t test

\begin{tabular}{cccccc}
\hline Kelompok & Pretest & Posttest & Mean \pm SD & N & p-value \\
\hline Kontrol & $6,00 \pm 1,57$ & $5,20 \pm 2,01$ & $0,80 \pm 1,64$ & 35 & \multirow{2}{*}{0,015} \\
Perlakuan & $5,74 \pm 1,75$ & $4,00 \pm 2,01$ & $1,74 \pm 1,52$ & 35 & \\
\hline
\end{tabular}

Pada Tabel III dapat dilihat nilai selisih penurunan skala nyeri kelompok kontrol dan kelompok perlakuan yaitu $0,80 \pm 1,64$ dan 1,74 $\pm 1,52$ dengan $p$-value $=0,015$. Karena $p$-value $0,015<0,05$ maka terdapat perbedaan skala nyeri yang signifikan antara kelompok kontrol dan kelompok perlakuan yang tidak diberikan perlakuan dengan kelompok perlakuan berupa suplemen kombinasi kalsium.

Hasil ini senada dengan penelitian yang dilakukan oleh Sinaga (2012) yang menyatakan bahwa terdapat hubungan antara asupan kalsium dengan kejadian dismenorea pada remaja putri salah satu vihara di Medan. Hasil penelitian serupa juga ditunjukkan pada penelitian Simorangkir (2016) yang menyebutkan bahwa terdapat hubungan yang signifikan antara asupan kalsium terhadap dismenorea $(p<0,05)$. Keterbaruan penelitian ini dengan penelitian terdahulu adalah adanya kombinasi kalsium dengan vitamin $\mathrm{D}$, vitamin $\mathrm{B} 6$, dan vitamin $\mathrm{C}$ dalam satu sediaan tablet effervescent.

Kalsium merupakan zat yang penting dan sangat diperlukan dalam kontraksi otot. Kalsium yang dikonsumsi dengan kadar yang cukup akan sangat berpengaruh dalam siklus menstruasi wanita. Apabila kekurangan kalsium, maka otot tersebut akan sulit mengendur dan terjadi kram perut yang berakibat terjadinya nyeri (Bertone-Jonhson, 2018). Selain itu, di dalam suplemen kalsium dalam sediaan yang digunakan dalam penelitian ini juga terdapat vitamin B6, vitamin D, dan vitamin C. Vitamin-vitamin tersebut juga memiliki peran yang cukup penting para proses penurunan skala nyeri dismenorea pada responden. Bertone-Jonhson (2018) melakukan studi prospektif yang menemukan bahwa wanita yang memiliki asupan tinggi vitamin $\mathrm{D}$ dan kalsium memiliki resiko terjadinya nyeri dismenorea yang lebih rendah dibandingkan dengan wanita yang meiliki asupan kalsium yang rendah.

Penelitian yang dilakukan oleh Moini et al. (2016) juga menyatakan bahwa konsumsi vitamin D pada wanita dengan nilai asupan vitamin D yang kurang mendapatkan hasil yang signifikan dapat mengurangi gejala dismenorea. Hal tersebut 
dikarenakan vitamin D dapat bertindak dengan mekanisme yang berbeda di endomentrium. Pada endometrium, vitamin D akan mengurangi ekspresi enzim Cyclo Oxigenase $(\mathrm{COX})$, meningkatkan aktivasi prostaglandin, serta mengatur ekspresi reseptor prostaglandin yang akan berakibat pada berkurangnya intensitas nyeri.

Saeedian et al. (2015) juga memaparkan bahwa konsumsi kalsium yang cukup dapat mengakibatkan terjadinya penurunan yang signifikan terhadap gejala-gejala somatik yang dialami pada saat menstruasi salah satunya adalah sakit kepala, nyeri sendi, beberapa gangguan emosional seperti pengurangan nafsu makan, depresi, dan gangguan tidur. Penelitian yang dilakukan oleh Fikriya et al. (2017) juga menunjukkan hasil bahwa terdapat pengurangan tingkat kecemasan yang dialami oleh responden setelah mengonsumsi vitamin B6 dengan penurunan yaitu kecemasan sedang menurun dari prosentase $71,4 \%$ menjadi $35,7 \%$ dan yang mengalami kecemasan ringan meningkat dari $28,6 \%$ menjadi $64,3 \%$. Hal ini membuktikan bahwa konsumsi suplemen kombinasi kalsium dengan beberapa vitamin diatas yakni vitamin B6, vitamin, $\mathrm{C}$ dan vitamin $\mathrm{D}$ dapat mempengaruhi penurunan intensitas nyeri subjek penelitian.

\section{KESIMPULAN}

Pemberian suplemen kombinasi kalsium berpengaruh terhadap penurunan skala nyeri dismenorea yang ditunjukkan dengan penurunan skala VAS pada kelompok kontrol dan perlakuan masing-masing sebesar $0,80 \pm 1,64$ dan 1,74 $\pm 1,52$ ( $p$-value 0,015 ).

\section{DAFTAR PUSTAKA}

Bertone-Johnson ER, Hankinson SE, Bendich A, Johnson SR, Willett WC, Manson JE, 2010, Calcium and vitamin D Intake And Risk of Incident Premenstrual Syndrome, Archives of Internal Medicine;165:1246-52.

Bonde, Fitra MP, and Maya Moningka, 2014, Pengaruh Kompres Panas Terhadap Penurunan Derajat Nyeri Haid Pada Siswi SMA dan SMK Yadika Kopandakan II, Jurnal E-Biomedik 2 (1).

Fen Tih, Cherry Azaria, Julia Windi Gunadi, Rizna Tyrani Rumanti, Alfred Tri Susanto, Alissa Amelia Santoso, and Firsty Tasya Evitasari, 2017, Efek Konsumsi Suplemen Kalsium dan Magnesium Terhadap Dismenore Primer dan Sindrom Premenstruasi Pada Perempuan Usia 19-23 Tahun, Global Medical \& Health Communication (GMHC) 5 (3): 159.

Fikriya, Ulul, Yeni Agus Safitri, and Tut Rayani Aksohini Wijayanti, 2017, Pemberian Vitamin B6 Sebagai Upaya Mengurangi Kecemasan Pada Remaja Akhir dengan Premenstruasi Syndrom, Jurnal Kesehatan Hesti Wira Sakti 4 (2): 102-109.

Jensen, M.P., Chen, C., Brugger, A.M., 2003, Interpretation of Visual Analog Scale Ratings and Change Scores: A Reanalysis of Two Clinical Trials of Postoperative Pain, The Journal of Pain, Vol. 4 (7), 407-414.

Lestari, Ni Made Sri Dewi, 2013, Pengaruh Dismenorea Pada Remaja, Prosiding Seminar Nasional MIPA 0 (0).

Mahmudiono, T, 2011, Fiber, PUFA, and Calcium Intake is Associated With The Degree of Primary Dysmenorrhea In Adolescent Girl Surabaya, Indonesia, Journal of Obstretics \& Gynecology. 
Moini, Ashraf, Tabandeh Ebrahimi, Nooshin Shirzad, Reihaneh Hosseini, Mania Radfar, Fatemeh Bandarian, Shahrzad Jafari-Adli, Mostafa Qorbani, and Mahboobeh Hemmatabadi, 2016, "The Effect of Vitamin D on Primary Dysmenorrhea with Vitamin D Deficiency: A Randomized Double-Blind Controlled Clinical Trial.Gynecological Endocrinology 32 (6): 502-5.

Munawaroh, Khoirunnisa', Untung Sujianto, and Mardiyono Mardiyono, 2017, Modifikasi Pro Self Pain Control Untuk Menurunkan Nyeri Dan Meningkatkan Kemampuan Aktivitas Pada Pasien Kanker Kolorektal Yang Menjalani Kemoterapi, PhD Thesis, Faculty of Medicine.

Proverawati and Misaroh, 2009, Menarche (Menstruasi Pertama Penuh Makna). Jakarta: Nuha Medika, Halaman: 97-112.

Saeedian Kia, Afsaneh, Reza Amani, and Bahman Cheraghian, 2015, The Association between the Risk of Premenstrual Syndrome and Vitamin D, Calcium, and Magnesium Status among University Students: A Case Control Study, Health Promotion Perspectives 5 (3): 225-30.

Sianipar, Olaf, Nur Chandra Bunawan, Prima Almazini, Neysa Calista, Priyandini Wulandari, Natasha Rovenska, Raissa E. Djuanda, Irene Irene, Seno Adjie, and Eva Suarthana, 2011, Prevalence of Menstrual Disorder and Associated Factors of Female Students at High School in Pulo Gadung Subdistrict of East Jakarta, Journal of the Indonesian Medical Association 59 (07).

Simorangkir, Vina Edika Rosmawati, 2016, Hubungan Asupan Kalsium, Magnesium, Dan Kebiasaan Olahraga Terhadap Dismenore Pada Siswi SMPN 191 Kebun Jeruk Jakarta Barat, Skripsi, Universitas Esa Unggul.

Sinaga, Fitriani Br, 2012, "Hubungan Asupan Kalsium Dengan Tingkat Dismenore Pada Remaja Putri Vegan Di Vihara Maitreya Medan Tahun 2011", Skripsi, Universitas Sumatera Utara.

Soviana, Elida, Putri Apriana Dea, 2017, Hubungan Asupan Vitamin B6 dan Kalsium dengan Kejadian Sindrom Premenstruasi Pada Siswi di SMA N Colomadu. The 5th Urecol Proceeding.

Wiknjosastro, Hanifa, 2007, Ilmu kebidanan. Yayasan Bina Pustaka. Halaman: 133140. 